\title{
Virus-induced gene silencing is a versatile tool for unraveling the functional relevance of multiple abiotic-stress-responsive genes in crop plants
}

\author{
Venkategowda Ramegowda ${ }^{1+}$, Kirankumar S. Mysore ${ }^{2}$ and Muthappa Senthil-Kumar ${ }^{3 *}$ \\ 1 Department of Crop Physiology, University of Agricultural Sciences, GKVK, Bangalore, India \\ 2 Plant Biology Division, The Samuel Roberts Noble Foundation, Ardmore, OK, USA \\ ${ }^{3}$ National Institute of Plant Genome Research, New Delhi, India
}

\section{Edited by:}

Mukesh Jain, National Institute of

Plant Genome Research, India

Reviewed by:

Vagner Benedito, West Virginia

University, USA

Matthew R. Willmann, University of

Pennsylvania, USA

*Correspondence:

Muthappa Senthil-Kumar, National Institute of Plant Genome Research, JNU Campus, Aruna Asaf Ali Marg, PO Box No. 10531

New Delhi 110 067, India

e-mail:skmuthappa@nipgr.ac.in

${ }^{\dagger}$ Present address:

Venkategowda Ramegowda

Department of Crop, Soil and

Environmental Sciences, University

of Arkansas, Fayetteville, USA
Virus-induced gene silencing (VIGS) is an effective tool for gene function analysis in plants. Over the last decade, VIGS has been successfully used as both a forward and reverse genetics technique for gene function analysis in various model plants, as well as crop plants. With the increased identification of differentially expressed genes under various abiotic stresses through high-throughput transcript profiling, the application of VIGS is expected to be important in the future for functional characterization of a large number of genes. In the recent past, VIGS was proven to be an elegant tool for functional characterization of genes associated with abiotic stress responses. In this review, we provide an overview of how VIGS is used in different crop species to characterize genes associated with drought-, salt-, oxidative- and nutrient-deficiency-stresses. We describe the examples from studies where abiotic stress related genes are characterized using VIGS. In addition, we describe the major advantages of VIGS over other currently available functional genomics tools. We also summarize the recent improvements, limitations and future prospects of using VIGS as a tool for studying plant responses to abiotic stresses.

Keywords: abiotic stress, functional genomics of crop plants, plant viruses, post-transcriptional gene silencing, virus-induced gene silencing

\section{INTRODUCTION}

The recent advances in next-generation sequencing technology has enabled sequencing of stress-specific transcriptomes and genomes of stress tolerant and susceptible cultivars (Morozova and Marra, 2008). Furthermore, an inventory of genes showing altered expression under several abiotic stresses has been established for many crop species by expressed sequence tag (EST) analysis (Gorantla et al., 2007; Wani et al., 2010; Blair et al., 2011). In contrast to the enormous progress made in generating sequence information, functional analysis of genes is lagging behind. Although in silico approaches and comparative genomic strategies have provided initial clues about the identity and function of abiotic-stress-responsive genes in many crop species (Gorantla et al., 2007; Tran and Mochida, 2010; Soares-Cavalcanti et al., 2012), comprehensive functional characterization tools are necessary for understanding the precise role of these genes in combating abiotic stresses. Mutant plants generated by chemical mutagenesis (Saleki et al., 1993), T-DNA tagging (Koiwa et al., 2006), and transposon tagging (Zhu et al., 2007) have been used for understanding stress tolerance. However, the generation of large-scale mutant populations requires tedious and laborious efforts, and identification of mutated genes is a lengthy process. RNAi is another tool used for studying the functional relevance of various abiotic-stress-related genes (Guo et al., 2002; Senthil-Kumar and Udayakumar, 2010), but this requires time-consuming genetic transformation. Therefore, in order to quickly study the function of a large number of genes identified through abiotic-stress-specific transcriptome profiles in several crop species and their wild relatives, alternative high-throughput tools are needed. Virus-induced gene silencing (VIGS) has emerged as a successful gene knockdown technique in several crop species in part because it does not require transformation (Baulcombe, 1999; Burch-Smith et al., 2004; Senthil-Kumar and Mysore, 2011a) (Supplementary Table 1). Over the past several years, VIGS has been successfully used to understand the abiotic stress tolerance mechanisms in crop plants (Senthil-Kumar and Udayakumar, 2006; Senthil-Kumar et al., 2008; Manmathan et al., 2013). In this review, we discuss the utility of this powerful technique to study genes involved in abiotic stress tolerance. We also discuss the mechanism of VIGS and list the VIGS vectors available for a wide range of crops and novel ways for application of VIGS to carry out functional analysis of abiotic-stress-responsive genes. Further, the recent improvements in VIGS protocol, limitations and future prospects are discussed.

\section{MECHANISM OF VIGS AND GENESIS OF VIGS VECTORS}

VIGS is a post-transcriptional gene silencing (PTGS)-based technique (Baulcombe, 1999), and it exploits the natural defense mechanisms employed by plants to protect against invading viruses (Voinnet, 2001). Plants infected by viruses induce double 
stranded RNA (dsRNA) mediated PTGS which degrades viral RNAs. For VIGS, the viral genomes are modified by removing genes which induce virus symptoms and cloning the cDNAs of viral genomes into binary vectors under CaMV35S promoter along with convenient multiple cloning sites to facilitate insertion of target gene fragments (Voinnet, 2001; Liu et al., 2002a,b). Viruses that do not have suppressors of gene silencing or have only weak suppressors are modified as VIGS vectors to induce PTGS-mediated degradation of target plant mRNAs (Li and Ding, 2001; Cao et al., 2005). VIGS vectors are constructed by cloning a fragment (usually 300-500-bp) of the plant target gene with efficient siRNA generation and no off-target genes into the modified viral genome (http://bioinfo2.noble.org/RNAiScan.htm) (Xu et al., 2006). The recombinant virus is then introduced into plant cells through Agrobacterium tumefaciens-mediated transient expression or in vitro transcribed RNA inoculation or direct DNA inoculation (Supplementary Table 2). After the recombinant virus is introduced into plant cells, the transgene is amplified along with the viral RNA by either an endogenous or a viral RNA-dependent RNA polymerase ( $\mathrm{RdRp}$ ) enzyme generating dsRNA molecules (Dalmay et al., 2000; Mourrain et al., 2000). These dsRNA intermediates are then recognized by DICER-like enzymes which cleave dsRNA into small interfering RNAs (siRNAs) of 21- to 25-nucleotides (Deleris et al., 2006). The double stranded siRNAs are then recognized by the RISC complex. The RISC complex uses the single stranded siRNAs and identifies complementary RNA sequences in the cell and degrades them (Fagard et al., 2000; Morel et al., 2002) (Supplementary Figure 1). VIGS has been shown to occur for a shorter period of approximately 3 weeks and the efficiency decreases after a month resulting in partial or complete recovery of plants from the silencing (Ratcliff et al., 2001; Hiriart et al., 2003; Ryu et al., 2004) (Supplementary Figure 2A). However, recent evidences suggest that some VIGS vectors can be used to maintain the gene silencing for several months by suitably modifying plant growth conditions that favor viral multiplication (Fu et al., 2006; Tuttle et al., 2008; Senthil-Kumar and Mysore, 2011b, 2014) (Supplementary Figure 2B) and can transmit to next generation (Senthil-Kumar and Mysore, 2011b) behaving like stable transgenic plants (Supplementary Figure 2C).

To date, about 35 DNA or RNA viruses have been modified as VIGS vectors (Senthil-Kumar and Mysore, 2011a). The VIGS vector resources available for crop plants are listed in Supplementary Table 1. Interestingly, the ability of certain viruses to infect a large number of host plants enabled the use of a single VIGS vector for gene silencing in several plant species (Robertson, 2004). For example, Tobacco rattle virus (TRV)-based VIGS vector is one of the most widely used VIGS vectors due to its ability to infect a wide range of host plants, systemic spread throughout the host plant including meristem, and lack of severe virus-associated symptoms in the infected plant (Valentine et al., 2004; Martín-Hernández and Baulcombe, 2008). TRV is a positive single stranded RNA virus with bipartite genome (RNA1 and RNA2). The RNA1 contains genes encoding RNA-dependent RNA polymerase, movement protein and $16 \mathrm{~K}$ cysteine rich protein (Macfarlane, 1999). The RNA2 contains gene encoding coat protein and restriction sites for cloning the gene of interest (Liu et al., 2002b). Successful TRV-based VIGS requires infiltration of both RNA1 and RNA2 components. The TRV-based vector has been successfully demonstrated in functional analysis of abioticstress-responsive genes in model plants like Nicotiana benthamiana (Senthil-Kumar et al., 2007) and crop plants like tomato (Solanum lycopersicum and S. pimpinellifolium) (Senthil-Kumar and Udayakumar, 2006; Li et al., 2013; Virk et al., 2013), chili pepper (Capsicum annuum) (Lee et al., 2010; Choi and Hwang, 2012; Lim and Lee, 2014) and rose (Rosa hybrid) (Dai et al., 2012; Liu et al., 2013; Jiang et al., 2014).

Another source of VIGS vectors used for silencing of abiotic stress genes are the novel two-component system based on satellite-viruses along with helper viruses. In nature satelliteviruses are totally dependent on other viruses for replication (Tao and Zhou, 2004; Cai et al., 2007). An example of the DNA virus based two-component system is a satellite-virus-based vector, DNA $\beta$, which was used along with Tomato yellow leaf curl china virus (TYLCCNV) as a helper virus to study the genes involved in abiotic stress responses in tomato (He et al., 2008; Guo et al., 2010). DNA $\beta$ satellite virus is devoid of the undesired effects of virus infection and instead functions to deliver the target gene fragment. RNA virus based VIGS systems with satellite and helper RNAs have also been developed. Here the satellite virus vector helps to deliver RNA into plants and the helper viruses supply replication and movement proteins. The advantage of twocomponent system is, it produces stronger silencing phenotypes compared to the satellite viruses alone (Gosselé et al., 2002).

In contrast to dicotyledonous plants, monocotyledonous plants have only a few VIGS vectors to date (Scofield and Nelson, 2009; Hema et al., 2013). Among these, the Barley stripe mosaic virus (BSMV)-based vector is the most widely used VIGS vector for functional analysis of abiotic stress genes in wheat (Triticum aestivum) (Kuzuoglu-Ozturk et al., 2012; Kang et al., 2013; Manmathan et al., 2013) and barley (Hordeum vulgare) (Liang et al., 2012). The availability of other vector resources and the potential of VIGS in monocotyledonous species have been comprehensively reviewed recently (Scofield and Nelson, 2009; Hema et al., 2013).

\section{RECENT IMPROVEMENTS IN VIGS}

Apart from a number of new VIGS vectors developed to suit a wide range of crop species, existing VIGS vectors and the technique have undergone several improvements in the recent past. For example, viral vectors have been modified to improve silencing efficiency. Recently, the RNA1 component of the bipartite TRV-vector was modified to serve as a VIGS vector which can infect plants systemically in the absence of RNA2 (Deng et al., 2013). This vector was developed by partially removing the $16 \mathrm{~K}$ cysteine rich protein. The advantage of $16 \mathrm{~K}$ protein removal is that it creates space for target gene cloning which otherwise cloned in RNA2 and also reduces the silencing suppression capacity of TRV. Furthermore, attempts have been made to identify gene-silenced tissues through a VIGS vector. For example, a GREEN FLUORESCENT PROTEIN (GFP) gene has been tagged to the coat protein gene of TRV2 for easy identification of silenced tissue (Tian et al., 2014). This will help in tracing only green fluorescent tissues that have the virus, which are 
expected to have silencing, and hence facilitate the use of these tissues for abiotic stress assays. Some VIGS vectors have also been used to induce transcriptional gene silencing (TGS). Cloning of endogenous target gene promoter into viral vector and delivery into plants results in the production of siRNAs homologous to the endogenous gene promoter. These siRNAs facilitate RNAdirected DNA methylation (RdDM) and histone modifications, resulting in RNA-mediated gene silencing (Kanazawa et al., 2011). This can help suppress the regulators of abiotic stress response. In addition to improvements in VIGS vectors, VIGS procedure has been modified to perform silencing in different tissues. Gene silencing has been demonstrated in detached plant parts like petals (Dai et al., 2012), leaves and fruits (Romero et al., 2011; Ramegowda et al., 2013). This will facilitate high-throughput silencing and multiple stress impositions. VIGS has also been used to silence genes during tissue culture and callus development (Anand et al., 2007) which can facilitate precise stress imposition and high-throughput screening.

\section{VIGS FOR STUDYING ABIOTIC STRESS RESPONSES IN CROP SPECIES}

VIGS has been used to investigate gene functions under abiotic stresses in model species. These studies involving model plants (Ahn et al., 2006; Moeder et al., 2007; Qian et al., 2007; SenthilKumar et al., 2007; Ahn and Pai, 2008; Cho et al., 2008; Hong et al., 2008; Sarowar et al., 2008; Govind et al., 2009; Ré et al., 2011) are not discussed in this review; instead, the main focus is given to studies involving crop plants. Recently, development of a wide range of VIGS vectors with high silencing efficiency has expanded the application of VIGS to several crop species for studying abiotic-stress-responsive genes (Table 1). The following sections enumerate the studies in which VIGS was used to characterize abiotic-stress-responsive genes in crop plants.

\section{DROUGHT STRESS TOLERANCE}

VIGS is a valuable tool for functional validation of droughtresponsive genes identified from transcript profiling of plants exposed to drought stress. TRV-VIGS-mediated silencing of lea4, a gene encoding late embryogenesis abundant protein (LEA), resulted in increased susceptibility of tomato plants to drought stress. This gene was identified from a subtracted cDNA library for drought-stress-responsive genes (Gopalakrishna et al., 2001). At a given drought stress level, lea4-silenced plants wilted faster and recovered slower upon re-watering than the wild-type and vector control plants. lea4-silenced plants also exhibited reduced osmotic adjustment, reduced cell viability and higher superoxide radical levels (Senthil-Kumar and Udayakumar, 2006). In another study, a GLUTAREDOXIN gene, SlGRX1, was shown to regulate the drought stress response in tomato using a satellite-virus-based vector, DNAm $\beta$ (Guo et al., 2010). Under drought stress, silenced plants showed decreased chlorophyll content and decreased relative water content (RWC) compared to vector control plants (Guo et al., 2010). To study the role of mitogen-activated protein kinases (MAPKs) in drought tolerance of $S$. pimpinellifolium, a wild species of tomato, SpMPK1, SpMPK2, and SpMPK3 genes were silenced individually or together using TRV-VIGS. Results suggested that co-silencing of SpMPK1/SpMPK2 impaired
ABA- and $\mathrm{H}_{2} \mathrm{O}_{2}$-induced stomatal closure and enhanced ABAinduced $\mathrm{H}_{2} \mathrm{O}_{2}$ production. But this response was not seen when SpMPK1 and SpMPK2 were silenced individually, suggesting these two genes are functionally redundant. This indicates that VIGS can be used to study functionally redundant genes. Reduced drought tolerance was also seen in SpMPK3 alone and SpMPK1/SpMPK2/SpMPK3 co-silenced plants (Li et al., 2013). Similarly, silencing of the SIMPK4 gene in tomato resulted in early wilting and reduced tolerance of plants to drought stress (Virk et al., 2013). TRV-VIGS-mediated silencing of extracellular PEROXIDASE 2 (CaPO2) in chili pepper resulted in increased susceptibility of silenced plants to mannitol-induced osmotic stress. Leaf disks from CaPO2-silenced leaves showed severe bleaching and higher chlorophyll loss than vector control plants (Choi and Hwang, 2012). Similarly, silencing of the $A B I 3 / V P 1$ transcription factor $(C a R A V 1)$ alone or together with OXIDOREDUCTASE (CaOXR1), using the TRV-VIGS vector, conferred reduced tolerance to mannitol-induced osmotic stress compared to vector control plants (Lee et al., 2010). This was accompanied by reduced expression of the known drought-stressresponsive genes ANTIMICROBIAL PROTEIN (CaAMP1) and OSMOTIN (CaOSM1) (Hong et al., 2004; Lee and Hwang, 2009). A recent study (Lim and Lee, 2014) implicated the involvement of MILDEW RESISTANCE LOCUS O (CaMLO2) in drought tolerance in chili pepper. Silencing of CaMLO2 using the TRV-VIGS vector in chili pepper plants showed lower levels of transpirational water loss and lipid peroxidation in dehydrated leaves compared to wild-type plants. This study showed that CaMLO2 acts as a negative regulator under drought stress conditions.

Another study demonstrated the usefulness of the TRVbased VIGS technique to study dehydration-responsive genes in rose flowers. Individual silencing of the NAC TRANSCRIPTION FACTOR 2 (RhNAC2) and A-TYPE EXPANSIN 4 (RhEXPA4) in rose petals and petal disks reduced the recovery of petals and petal disks during rehydration (Dai et al., 2012). Similarly, silencing of NAC TRANSCRIPTION FACTOR 3 (RhNAC3) in rose petals has resulted in a decrease in cell expansion of the petals during rehydration along with concomitant downregulation of several stress- and cell-expansion-related genes in the silenced petals compared to the vector control (Jiang et al., 2014). These genes are possible candidates for improving the shelf life of rose flowers through reduced water loss. Silencing of the ACC SYNTHASE 1 (RhACS1) and ACC SYNTHASE 2 (RhACS2) genes individually or co-silencing of both genes suppressed dehydration- and rehydration-induced ethylene in the sepals and gynoecia. Reduced ethylene production resulted in improved petal cell expansion during dehydration. On the contrary, silencing of an ethylene receptor, RhETR3, enhanced the inhibitory effect of dehydration on petal cell expansion (Liu et al., 2013). These results suggest that ethylene mediates dehydrationinduced inhibition of cell expansion in rose petals.

VIGS has also been used to study drought stress response in monocotyledonous crop species. In a recent study (Manmathan et al., 2013), two drought-stress-responsive genes, ENHANCED RESPONSE TO ABSCISIC ACID (Era1) and INOSITOL POLYPHOSPHATE 1-PHOSPHATASE (Sal1), were individually silenced in wheat using the BSMV-VIGS vector. Eral gene 
Table 1 | List of abiotic-stress-related genes silenced in crop plants using VIGS.

\begin{tabular}{|c|c|c|c|c|c|}
\hline $\begin{array}{l}\text { VIGS } \\
\text { vector }\end{array}$ & $\begin{array}{l}\text { Crop } \\
\text { species }\end{array}$ & Silenced target gene & Abiotic stress & $\begin{array}{l}\text { Changes in gene-silenced } \\
\text { plants exposed to stress } \\
\text { (compared to vector control } \\
\text { plants) }\end{array}$ & References \\
\hline \multirow[t]{4}{*}{ BSMV } & \multirow[t]{2}{*}{ Wheat } & $\begin{array}{l}\text { TaEra1 (ENHANCED RESPONSE TO } \\
\text { ABSCISIC ACID), TaSal1 (INOSITOL } \\
\text { POLYPHOSPHATE 1-PHOSPHATASE) }\end{array}$ & Drought & $\begin{array}{l}\text { Increased relative water content } \\
\text { (RWC), increased water use } \\
\text { efficiency (WUE), reduced } \\
\text { stomatal conductance, reduced } \\
\text { transpiration rate and higher } \\
\text { plant vigor }\end{array}$ & $\begin{array}{l}\text { Manmathan et al., } \\
2013\end{array}$ \\
\hline & & $\begin{array}{l}\text { TaBTF3 (BASIC TRANSCRIPTION } \\
\text { FACTOR 3) }\end{array}$ & Drought & $\begin{array}{l}\text { Wilted and curled leaves under } \\
\text { severe drought, higher water } \\
\text { loss rate (WLR), decreased } \\
\text { RWC and survival rate, lower } \\
\text { free proline content, and } \\
\text { increased membrane leakage }\end{array}$ & Kang et al., 2013 \\
\hline & $\begin{array}{l}\text { Wild } \\
\text { emmer } \\
\text { wheat }\end{array}$ & TdAtg8 (AUTOPHAGY-RELATED 8) & Drought & $\begin{array}{l}\text { Decreased chlorophyll content } \\
\text { and increased MDA }\end{array}$ & $\begin{array}{l}\text { Kuzuoglu-Ozturk } \\
\text { et al., } 2012\end{array}$ \\
\hline & Barley & $\begin{array}{l}\text { HVHVA1 (H. VULGARIS ABUNDANT } \\
\text { PROTEIN) }\end{array}$ & Drought & $\begin{array}{l}\text { Higher WLR in detached leaves, } \\
\text { less survival, and retarded } \\
\text { growth with reduced height and } \\
\text { less total dry weight }\end{array}$ & Liang et al., 2012 \\
\hline \multirow[t]{3}{*}{ PEBV } & \multirow[t]{3}{*}{ Pea } & PsSym19 (SYMBIOTIC) & $\begin{array}{l}\text { Arbuscular- mycorrhizal- } \\
\text { symbiosis-associated Pi } \\
\text { uptake }\end{array}$ & $\begin{array}{l}\text { Less development of arbuscules } \\
\text { and vesicles in the root cortex } \\
\text { of silenced plants }\end{array}$ & Grønlund et al., 2010 \\
\hline & & PSPT4 (PUTATIVE PI TRANSPORTER) & $\begin{array}{l}\text { Arbuscular-mycorrhizal- } \\
\text { symbiosis-associated Pi } \\
\text { uptake }\end{array}$ & $\begin{array}{l}\text { Reduced phosphate uptake in } \\
\text { new roots }\end{array}$ & Grønlund et al., 2010 \\
\hline & & TRX-F, TRX-M (THIOREDOXIN) & Oxidative stress & $\begin{array}{l}\text { Pale-green phenotype, } \\
\text { reduction in the following: Mg } \\
\text { chelatase activity, } \\
\text { 5-aminolevulinic acid synthesis, } \\
\text { chlorophyll, carotenoid pigment, } \\
\text { photosynthesis and expression } \\
\text { of tetrapyrrole biosynthesis } \\
\text { pathway genes and increased } \\
\text { accumulation of ROS }\end{array}$ & Luo et al., 2012 \\
\hline
\end{tabular}


Table 1 | Continued

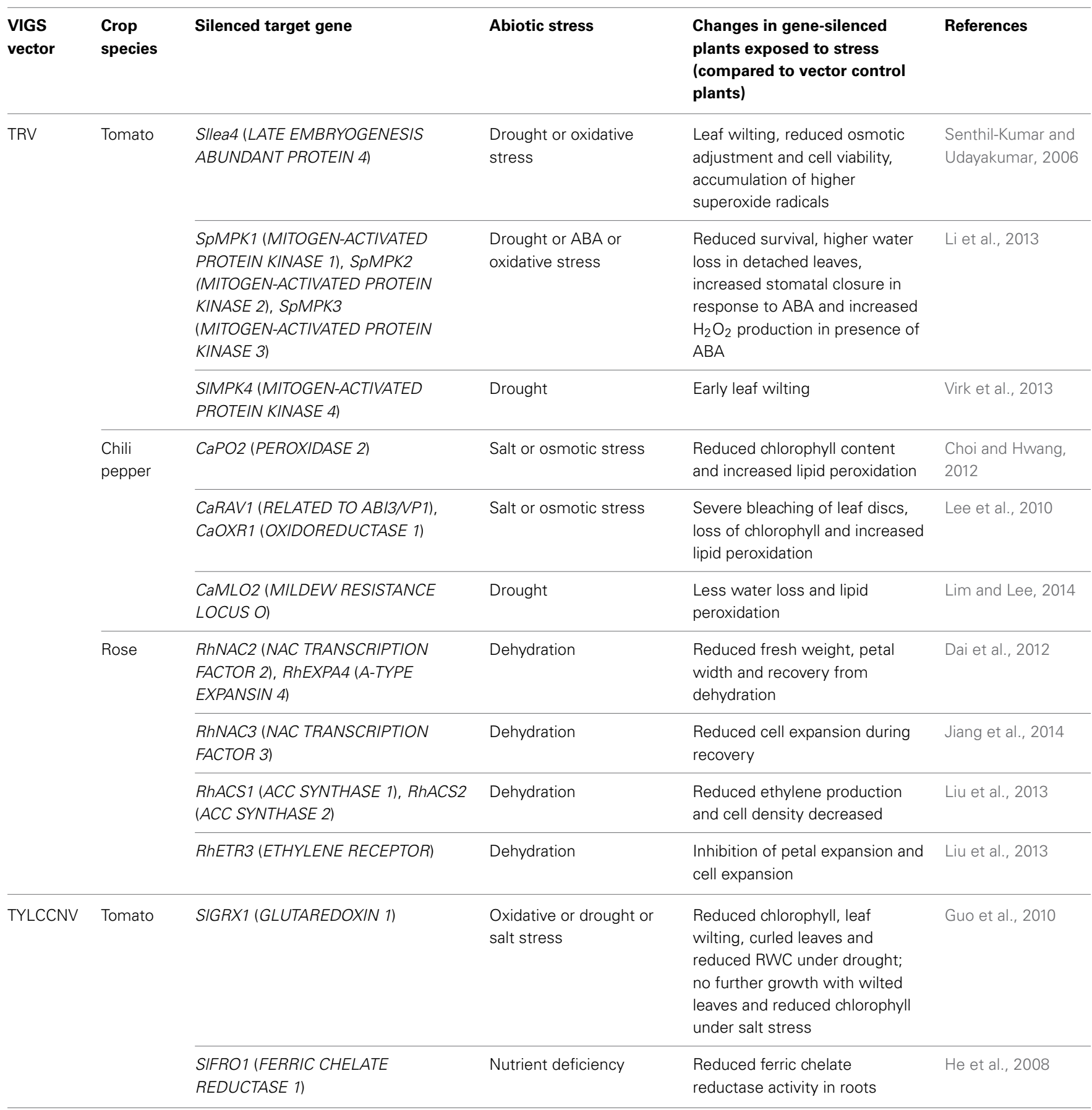

encodes the $\beta$-subunit of farnesyltransferase involved in ABA mediated stomatal closure by activating the guard cell S-type anion-channels and increasing the cytosolic $\mathrm{Ca}^{2+}$ concentration. The loss-of-function of Eral has been shown to enhance ABA sensitivity and hence reduced stomatal conductance and water loss (Cutler et al., 1996; Allen et al., 2002; Wang et al., 2005). Similarly, Sal1 has been shown to act as a negative regulator of both $\mathrm{ABA}$-independent and $\mathrm{ABA}$-dependent stress response pathways. Its loss-of-function has shown to increase the sensitivity of plants to drought stress (Wilson et al., 2009). Era1- and Sal1-silenced plants subjected to drought stress showed increased RWC, improved water use efficiency (WUE) and better vigor compared to vector-inoculated plants. This suggests that down-regulation of Eral and Sal1 genes enhances drought tolerance in wheat by decreasing sensitivity to ABA. In another study, H. VULGARIS ABUNDANT PROTEIN (HvHVA1) and DEHYDRIN 6 (HvDhn6), genes encoding the LEA class of proteins, were individually silenced in wheat using the BSMV-based 
VIGS vector (Liang et al., 2012). Under drought stress, both HVA1- and Dhn6-silenced plants showed lower survival rates than vector control plants. In addition, HVA1-silenced plants showed a higher rate of water loss under drought stress compared to vector control plants. However, the silenced plants also showed reduced vegetative growth and lower biomass even under well-watered conditions. This suggested the involvement of HvHVA1 and HvDhn6 in growth and development apart from drought tolerance (Liang et al., 2012). BSMV-VIGS-mediated silencing of the BASIC TRANSCRIPTION FACTOR 3 (TaBTF3) gene in wheat resulted in a decreased plant survival rate, less free proline content, less RWC and increased membrane leakage compared to vector control plants under drought stress (Kang et al., 2013). Similarly, BSMV-VIGS-mediated silencing of AUTOPHAGY-RELATED 8 (TdAtg8) from Triticum dicoccoides (wild emmer wheat) resulted in reduced chlorophyll content and an increase in malondialdehyde (MDA) content in silenced plants under drought stress (Kuzuoglu-Ozturk et al., 2012). The increased levels of MDA indicate membrane damage due to lipid peroxidation mainly by the effect of reactive oxygen species (ROS) (Zhang and Kirkham, 1994).

Taken together, these studies demonstrate the versatility of VIGS in deciphering the role of drought-stress-responsive genes in both dicotyledonous and monocotyledonous plants. In addition, the application of VIGS in silencing drought-stress-related genes in flowers (Dai et al., 2012) signifies its efficacy in studying the reproductive-tissue-associated genes which are important during terminal drought stress. Furthermore, VIGS has the potential to identify negative regulators of drought stress response during the reproductive stage.

\section{SALT-STRESS TOLERANCE}

The utility of VIGS in investigating salt stress tolerance in crop plants has also been demonstrated. SlGRX1 gene silencing in tomato by a satellite DNAm $\beta$-based VIGS vector resulted in yellowing of leaves under salinity stress compared to vector control plants due to a reduction in chlorophyll content, suggesting the role of GRX1 in salt tolerance (Guo et al., 2010). Further, the role of CaRAV1 and CaOXR1 has been studied by TRV-VIGS in chili pepper (Lee et al., 2010). Leaf disks from CaRAV1-only silenced and $C a R A V 1 / C a O X R 1$ co-silenced plants exposed to different concentrations of $\mathrm{NaCl}$ showed severe bleaching due to loss of chlorophyll compared to vector control plants. Similarly, TRV-VIGS-mediated silencing of CaPO2 resulted in a reduction in chlorophyll content and higher lipid peroxidation, leading to increased susceptibility of silenced chili pepper plants to salt stress compared to vector control plants (Choi and Hwang, 2012). Consistently, ectopic expression of $\mathrm{CaPO} 2$ in Arabidopsis conferred enhanced tolerance to high salt stress, suggesting the role of CaPO2 in salinity tolerance (Choi and Hwang, 2012). Taken together, these studies demonstrate the usefulness of VIGS in functional analysis of genes involved in salinity tolerance in crop plants.

\section{OXIDATIVE STRESS TOLERANCE}

ROS increases in plants challenged by drought, salinity, extreme temperatures, or high light stress (Pastori and Foyer, 2002); this in turn leads to oxidative stress (Apel and Hirt, 2004). VIGS has been used to study oxidative stress tolerance in the recent past. A few studies (Lee et al., 2010; Choi and Hwang, 2012) described earlier in this review that examined the role of chili pepper genes, like CaRAV1, $C a O X R 1$, and $C a P O 2$, have also described oxidative stress damage in the plants with these genes silenced. Silencing of CaRAV1, CaOXR1, or CaPO2 individually, or co-silencing of CaRAV1/CaOXR1 in chili pepper resulted in enhanced lipid peroxidation under stress (Lee et al., 2010; Choi and Hwang, 2012). Similarly, downregulation of CaMLO2 expression in chili pepper using TRV-based VIGS resulted in lower MDA levels under drought stress compared to vector control plants ( $\mathrm{Lim}$ and Lee, 2014). This indicated the plausible negative role of CaMLO2 under drought as well as oxidative stress. In wheat, silencing of TdAtg8 using BSMV-based VIGS resulted in higher MDA levels compared to vector control under drought stress, thus suggesting the possible involvement of TdAtg8 under oxidative stress (Kuzuoglu-Ozturk et al., 2012). High light stress induces oxidative stress in chloroplast. A recent study (Yuan-Ge et al., 2014) used BSMV-based VIGS to silence the PROTON GRADIENT REGULATION 5 (TaPGR5) gene in wheat to test its involvement in tolerance to photo-inhibition under high light treatment. High light inhibited the net photosynthesis and affected the maximal quantum yield of Photosystem II (Fv/Fm) in the silenced plants. Also, silenced plants showed increased membrane damage, anthocyanin accumulation and higher MDA, suggesting the role of TaPGR5 in oxidative stress tolerance. In pea, PEBV-VIGS-mediated co-silencing of thioredoxin genes, TRX$F / T R X-M$, resulted in a significant reduction in $\mathrm{Mg}$-chelatase activity and 5-aminolevulinic acid synthesizing capacity. This was associated with reduced chlorophyll and carotenoid pigment contents, lowered photosynthetic capacity and reduced expression of tetrapyrrole biosynthesis pathway genes, leading to the accumulation of ROS (Luo et al., 2012). Altogether, these studies highlight the utility of VIGS in characterizing the genes that mitigate oxidative stress in crop plants.

\section{VIGS FOR FUNCTIONAL ANALYSIS OF MINERAL NUTRITION-RELATED GENES IN CROP PLANTS}

Differential expression of a large number of genes in response to nutrient deficiency or toxicity has been shown in plants (Wang et al., 2002; Becher et al., 2004; Hirai et al., 2004; Takehisa et al., 2013), but only a few of them have been functionally characterized. In a soybean (Glycine max) iron-inefficient line, Isoclark, a Bean pod mottle virus (BPMV)-based VIGS vector was used to silence a REPLICATION PROTEIN A (GmRPA3) gene. GmRPA3-silenced plants had smaller leaves, decreased internode length and higher chlorophyll content, and failed to respond to increased iron nutrition, suggesting a role of the GmRPA3 gene in iron acquisition (Atwood et al., 2014). Using a satellite DNA (DNAm $\beta$ ) virus system with TYLCCNV, the function of FERRIC CHELATE REDUCTASE gene (FRO1) was studied in tomato roots (He et al., 2008). Silencing of FRO1 resulted in reduced ferric chelate reductase activity in roots. In pea (Pisum sativum), a Pea early browning virus (PEBV)-based vector was used to study arbuscular-mycorrhizal-fungi (AMF)-associated phosphate acquisition. Silencing of a symbiotic gene, PsSym19, reduced the 
development of both arbuscules and vesicles at the root cortex. Similarly, silencing of a putative Pi transporter gene, PsPT4, using the PEBV-vector, reduced the phosphate uptake (Grønlund et al., 2010), suggesting the importance of these genes in phosphate assimilation in pea plants. Taken together, these studies suggest that VIGS can be effectively used to analyze gene function associated with nutrient deficiency in crop plants.

\section{ADVANTAGES OF USING VIGS TO STUDY ABIOTIC STRESS TOLERANCE IN CROP PLANTS}

VIGS has several advantages over most established functional genomics tools (Burch-Smith et al., 2004; Purkayastha and Dasgupta, 2009; Unver and Budak, 2009; Stratmann and Hind, 2011; Pflieger et al., 2013). (1) VIGS is faster and relatively easy to perform. VIGS can produce loss-of-function phenotype of a specific gene in a short period resulting in rapid functional characterization of genes (Dinesh-Kumar et al., 2003). (2) VIGS avoids plant transformation. Functional characterization of genes in difficult to transform species would be more easier once the VIGS system is established in that species (Burch-Smith et al., 2004). (3) VIGS allows functional analysis of genes whose lossof-function produces lethal phenotype. It can be used to study genes related to embryonic development and seedling emergence and vigor (an important abiotic stress tolerance trait) (Ratcliff et al., 2001; Burch-Smith et al., 2004; Liu et al., 2004). (4) VIGS can overcome functional redundancy. Using the most conserved regions in VIGS, the multiple related genes or gene families can be silenced together (Ekengren et al., 2003; He et al., 2004). By silencing two or more members of the gene family with redundant functions the complex signaling components associated abiotic stresses such as drought can be deciphered. Though other functional genomics tools like antisense RNAs, artificial miRNAs, or RNAi can also be used for this purpose, but they are time consuming. (5) VIGS enables timely silencing of tissue-specific genes. For example, plants being infected only at the time of flowering or panicle development will predominantly have genes silenced in that organ. Besides, VIGS can be used to quickly silence genes in a particular gene mutant, stable RNAi or gene-overexpression plants. This will enable studying gene interactions under complex abiotic stresses in a large-scale and shorter time. In addition, VIGS is a feasible functional genomics tool over other PTGSmediated gene silencing methods (Supplementary Table 3). VIGS is versatile, which allows rapid comparisons of gene function between species and works in different genetic backgrounds where genetic transformation is tedious and time consuming. VIGS also serves as a high-throughput forward as well as reverse genetics tool in plants. VIGS as a high-throughput reverse genetics tool can be performed by individually cloning fragments (usually 300-500 base pairs) from a large number of target genes into a suitable viral vector. The viral vector is delivered into plants using different methods. Abiotic stress can be applied 2-3 weeks after inoculation and the loss-of-function phenotype can be studied in the silenced plants to attribute function for the target gene under abiotic stress (Supplementary Figure 3). Similarly, VIGS as a forward genetics tool enables identification of critical players in stress tolerance. The stress specific cDNA pool can be cloned into binary vectors and transformed into A. tumefaciens in a high-throughput manner (Liu et al., 2002b). Each Agro-clone is inoculated into individual plants using a feasible inoculation method. The Agro-clones which produce interesting phenotype under abiotic stress can be quickly identified and sequenced to identify the inserted gene (Supplementary Figure 4). In addition to several general advantages, VIGS has some advantages pertinent to characterizing abiotic-stress-responsive genes.

\section{LIMITATIONS OF VIGS IN STUDYING ABIOTIC STRESS TOLERANCE MECHANISMS AND SOLUTIONS TO OVERCOME THE LIMITATIONS}

Though VIGS has been proved to be a robust tool for functional genomics studies, it has several limitations. These limitations and ways to overcome the same are listed below. (1) The virus vector may accumulate to high levels in the silenced plant if the silenced target gene is involved in the immunity of plants against the virus and such plants can become highly susceptible to subsequent abiotic stress. This will adversely influence studying the specific effect of gene silencing on abiotic stress tolerance. Quantification of viral load (Senthil-Kumar and Mysore, 2011b) in the silenced plants helps to decide whether the virus has accumulated higher than in the non-silenced control plant and this information can be used to choose different region of the target gene for silencing. (2) Virus infection by itself can interfere with abiotic stress response. For example, infection of Brome mosaic virus (BMV), Cucumber mosaic virus (CMV), Tobacco mosaic virus (TMV) and TRV delayed the appearance of drought symptoms in various plant species (Xu et al., 2008). The VIGS vector along with abiotic stress can create a scenario like concurrent biotic and abiotic stress. The phenotype produced under this situation might be different from abiotic stress alone (Suzuki et al., 2014). This can be overcome by including appropriate non-silenced vector control plants and comparing the results with specific gene silenced plants. (3) Silencing can be affected by changes in environmental conditions during abiotic stress treatment. Temperature, relative humidity and light can influence silencing (Fu et al., 2005, 2006; Kotakis et al., 2010). VIGS efficiency is reduced under high temperatures due to reduced virus multiplication (Chellappan et al., 2005). This can be overcome by verifying the viral multiplication beforehand and maintaining the VIGS vector-inoculated plants under optimum environmental conditions until the silencing followed by abiotic stress imposition. Ways to overcome some of the limitations of VIGS to study abiotic-stress-associated genes are also described in our earlier review (Senthil-Kumar and Udayakumar, 2010).

\section{CONCLUSION AND FUTURE PROSPECTS}

VIGS, as both a forward and reverse genetics tool, offers opportunities for rapid functional analysis of abiotic-stress-related genes in both dicotyledonous and monocotyledonous crop species. Utilization of VIGS for understanding the mechanisms of abiotic stress tolerance and crop improvement is depicted in Figure 1. Currently, nearly 50 plant species have been shown to be amenable for VIGS (Lange et al., 2013), and VIGS is expected to be expanded to many other crop plants in future. Stress imposition protocols for VIGS plants have been optimized for several abiotic stresses, including drought, salinity and oxidative stress, 


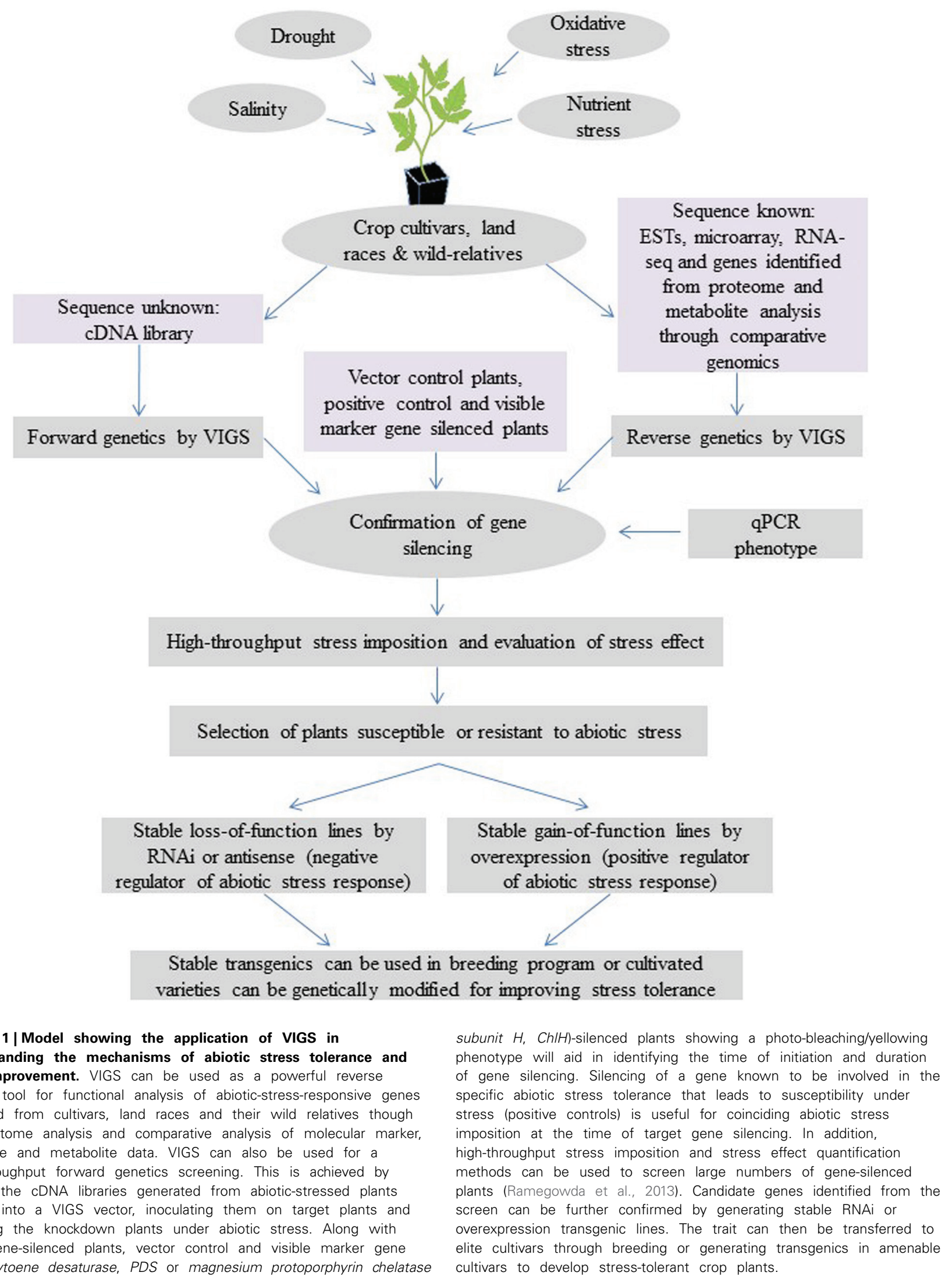


and extreme temperatures (Ramegowda et al., 2013). Recently, a modified virus vector has been developed to express artificial and endogenous miRNAs in plants (Tang et al., 2010). Virus-vectormediated silencing using artificial miRNA will be useful for functional analysis of abiotic-stress-associated miRNAs in crop plants. This approach will combine the specificity of amiRNA and versatility of VIGS. VIGS could also assist plant breeding programs in validating quantitative trait loci (QTL) and genes associated with abiotic stress traits (Cheng et al., 2010). Most of the QTL identified by molecular marker technologies would have multiple candidate genes. VIGS could serve as an effective and robust functional genomics tool to validate each gene in the locus. For example, a combination of cDNA-amplified fragment length polymorphism (AFLP) and VIGS can be used to screen a large number of genes and identify genes associated with abiotic stress tolerance. In summary, VIGS can play a major role in understanding abiotic stress tolerance mechanisms. This will have a direct impact on developing crop varieties that are tolerant to abiotic stress.

\section{AUTHOR CONTRIBUTIONS}

Venkategowda Ramegowda and Muthappa Senthil-Kumar wrote the manuscript, and Kirankumar S. Mysore edited the manuscript.

\section{ACKNOWLEDGMENTS}

VIGS-based projects at Muthappa Senthil-Kumar's laboratory are supported by core funding from the National Institute of Plant Genome Research and at Kirankumar S. Mysore's laboratory by The Samuel Roberts Noble Foundation. Authors thank Mr. Mehanathan Muthamilarasan and Dr. Aiswarya Baruah for critical reading of the manuscript and Ms. Jackie Kelley for help with editing the manuscript.

\section{SUPPLEMENTARY MATERIAL}

The Supplementary Material for this article can be found online at: http://www.frontiersin.org/journal/10.3389/fpls.2014.00323/ abstract

\section{REFERENCES}

Ahn, C. S., Lee, J. H., Reum Hwang, A., Kim, W. T., and Pai, H. S. (2006). Prohibitin is involved in mitochondrial biogenesis in plants. Plant J. 46, 658-667. doi: 10.1111/j.1365-313X.2006.02726.x

Ahn, C. S., and Pai, H. S. (2008). Physiological function of IspE, a plastid MEP pathway gene for isoprenoid biosynthesis, in organelle biogenesis and cell morphogenesis in Nicotiana benthamiana. Plant Mol. Biol. 66, 503-517. doi: 10.1007/s11103-007-9286-0

Allen, G. J., Murata, Y., Chu, S. P., Nafisi, M., and Schroeder, J. I. (2002). Hypersensitivity of abscisic acid-induced cytosolic calcium increases in the Arabidopsis Farnesyltransferase mutant era1-2. Plant Cell 14, 1649-1662. doi: 10.1105/tpc.010448

Anand, A., Vaghchhipawala, Z., Ryu, C. M., Kang, L., Wang, K., Del-Pozo, O., et al. (2007). Identification and characterization of plant genes involved in Agrobacterium-mediated plant transformation by virus-induced gene silencing. Mol. Plant Microbe. Interact. 20, 41-52. doi: 10.1094/MPMI-20-0041

Apel, K., and Hirt, H. (2004). Reactive oxygen species: metabolism, oxidative stress, and signal transduction. Annu. Rev. Plant Biol. 55, 373-399. doi: 10.1146/annurev.arplant.55.031903.141701

Atwood, S. E., O’Rourke, J. A., Peiffer, G. A., Yin, T., Majumder, M., Zhang, C., et al. (2014). Replication protein A subunit 3 and the iron efficiency response in soybean. Plant Cell Environ. 37, 213-234. doi: 10.1111/pce.12147
Baulcombe, D. C. (1999). Fast forward genetics based on virus-induced gene silencing. Curr. Opin. Plant Biol. 2, 109-113. doi: 10.1016/S1369-5266(99)80022-3

Becher, M., Talke, I. N., Krall, L., and Krämer, U. (2004). Cross-species microarray transcript profiling reveals high constitutive expression of metal homeostasis genes in shoots of the zinc hyperaccumulator Arabidopsis halleri. Plant J. 37, 251-268. doi: 10.1046/j.1365-313X.2003.01959.x

Blair, M. W., Fernandez, A. C., Ishitani, M., Moreta, D., Seki, M., Ayling, S., et al. (2011). Construction and EST sequencing of full-length, drought stress cDNA libraries for common beans (Phaseolus vulgaris L.). BMC Plant Biol. 11:171. doi: 10.1186/1471-2229-11-171

Burch-Smith, T. M., Anderson, J. C., Martin, G. B., and Dinesh-Kumar, S. P. (2004). Applications and advantages of virus-induced gene silencing for gene function studies in plants. Plant J. 39, 734-746. doi: 10.1111/j.1365-313X.2004. 02158.x

Cai, X., Wang, C., Xu, Y., Xu, Q., Zheng, Z., and Zhou, X. (2007). Efficient gene silencing induction in tomato by a viral satellite DNA vector. Virus Res. 125, 169-175. doi: 10.1016/j.virusres.2006.12.016

Cao, X., Zhou, P., Zhang, X., Zhu, S., Zhong, X., Xiao, Q., et al. (2005). Identification of an RNA silencing suppressor from a plant double-stranded RNA virus. J. Virol. 79, 13018-13027. doi: 10.1128/JVI.79.20.13018-13 027.2005

Chellappan, P., Vanitharani, R., Ogbe, F., and Fauquet, C. M. (2005). Effect of temperature on geminivirus-induced RNA silencing in plants. Plant Physiol. 138, 1828-1841. doi: 10.1104/pp.105.066563

Cheng, S. F., Huang, Y. P., Wu, Z. R., Hu, C. C., Hsu, Y. H., and Tsai, C. H. (2010). Identification of differentially expressed genes induced by Bamboo mosaic virus infection in Nicotiana benthamiana by cDNA-amplified fragment length polymorphism. BMC Plant Biol. 10:286. doi: 10.1186/1471-2229-10-286

Cho, S. M., Kang, B. R., Han, S. H., Anderson, A. J., Park, J. Y., Lee, Y. H., et al. (2008). 2R,3R-butanediol, a bacterial volatile produced by Pseudomonas chlororaphis $\mathrm{O6}$, is involved in induction of systemic tolerance to drought in Arabidopsis thaliana. Mol. Plant Microbe. Interact. 21, 1067-1075. doi: 10.1094/MPMI-21-8-1067

Choi, H. W., and Hwang, B. K. (2012). The pepper extracellular peroxidase CaPO2 is required for salt, drought and oxidative stress tolerance as well as resistance to fungal pathogens. Planta 235, 1369-1382. doi: 10.1007/s00425-011-1580-z

Cutler, S., Ghassemian, M., Bonetta, D., Cooney, S., and McCourt, P. (1996). A protein farnesyl transferase involved in abscisic acid signal transduction in Arabidopsis. Science 273, 1239-1241. doi: 10.1126/science.273.5279.1239

Dai, F., Zhang, C., Jiang, X., Kang, M., Yin, X., Lü, P., et al. (2012). RhNAC2 and RhEXPA4 are involved in the regulation of dehydration tolerance during the expansion of rose petals. Plant Physiol. 160, 2064-2082. doi: 10.1104/pp.112.207720

Dalmay, T., Hamilton, A., Rudd, S., Angell, S., and Baulcombe, D. C. (2000). An RNA-dependent RNA polymerase gene in arabidopsis is required for posttranscriptional gene silencing mediated by a transgene but not by a virus. Cell 101, 543-553. doi: 10.1016/S0092-8674(00)80864-8

Deleris, A., Gallego-Bartolome, J., Bao, J., Kasschau, K. D., Carrington, J. C., and Voinnet, O. (2006). Hierarchical action and inhibition of plant Dicer-like proteins in antiviral defense. Science 313, 68-71. doi: 10.1126/science.1128214

Deng, X., Kelloniemi, J., Haikonen, T., Vuorinen, A. L., Elomaa, P., Teeri, T. H., et al. (2013). Modification of Tobacco rattle virus RNA1 to serve as a VIGS vector reveals that the $29 \mathrm{~K}$ movement protein is an RNA silencing suppressor of the virus. Mol. Plant Microbe. Interact. 26, 503-514. doi: 10.1094/MPMI-12-120280-R

Dinesh-Kumar, S. P., Anandalakshmi, R., Marathe, R., Schiff, M., and Liu, Y. (2003). "Virus-induced gene silencing," in Plant Functional Genomics, ed E. Grotewold (New York, NY: Humana Press), 287-293.

Ekengren, S. K., Liu, Y., Schiff, M., Dinesh-Kumar, S. P., and Martin, G. B. (2003). Two MAPK cascades, NPR1, and TGA transcription factors play a role in Ptomediated disease resistance in tomato. Plant J. 36, 905-917. doi: 10.1046/j.1365313X.2003.01944.x

Fagard, M., Boutet, S., Morel, J. B., Bellini, C., and Vaucheret, H. (2000). AGO1, QDE-2, and RDE-1 are related proteins required for post-transcriptional gene silencing in plants, quelling in fungi, and RNA interference in animals. Proc. Natl. Acad. Sci. U.S.A. 97, 11650-11654. doi: 10.1073/pnas.200217597

Fu, D. Q., Zhu, B. Z., Zhu, H. L., Jiang, W. B., and Luo, Y. B. (2005). Virus-induced gene silencing in tomato fruit. Plant J. 43, 299-308. doi: 10.1111/j.1365313X.2005.02441.x 
Fu, D. Q., Zhu, B. Z., Zhu, H. L., Zhang, H. X., Xie, Y. H., Jiang, W. B., et al. (2006). Enhancement of virus-induced gene silencing in tomato by low temperature and low humidity. Mol. Cells 21, 153-160.

Gopalakrishna, R., Kumar, G., Krishnaprasad, B. T., Mathew, M. K., and Udayakumar, M. (2001). A stress-responsive gene from groundnut, Gdi15 , is homologous to flavonol 3-O-glucosyltransferase involved in anthocyanin biosynthesis. Biochem. Biophys. Res. Commun. 284, 574-579. doi: 10.1006/bbrc.2001.4992

Gorantla, M., Babu, P. R., Lachagari, V. B., Reddy, A. M., Wusirika, R., Bennetzen, J. L., et al. (2007). Identification of stress-responsive genes in an indica rice (Oryza sativa L.) using ESTs generated from drought-stressed seedlings. J. Exp. Bot. 58, 253-265. doi: 10.1093/jxb/erl213

Gosselé, V., Faché, I., Meulewaeter, F., Cornelissen, M., and Metzlaff, M. (2002). SVISS - a novel transient gene silencing system for gene function discovery and validation in tobacco plants. Plant J. 32, 859-866. doi: 10.1046/j.1365313X.2002.01471.x

Govind, G., Harshavardhan, V. T., Thammegowda, H. V., Patricia, J. K., Kalaiarasi, P. J., Dhanalakshmi, R., et al. (2009). Identification and functional validation of a unique set of drought induced genes preferentially expressed in response to gradual water stress in peanut. Mol. Genet. Genomics 281, 591-605. doi: 10.1007/s00438-009-0432-z

Grønlund, M., Olsen, A., Johansen, E. I., and Jakobsen, I. (2010). Protocol: using virus-induced gene silencing to study the arbuscular mycorrhizal symbiosis in Pisum sativum. Plant Methods 6, 28. doi: 10.1186/1746-4811-6-28

Guo, Y., Huang, C., Xie, Y., Song, F., and Zhou, X. (2010). A tomato glutaredoxin gene SIGRX1 regulates plant responses to oxidative, drought and salt stresses. Planta 232, 1499-1509. doi: 10.1007/s00425-010-1271-1

Guo, Y., Xiong, L., Song, C. P., Gong, D., Halfter, U., and Zhu, J. K. (2002). A calcium sensor and its interacting protein kinase are global regulators of abscisic acid signaling in Arabidopsis. Dev. Cell 3, 233-244. doi: 10.1016/S15345807(02)00229-0

He, X., Anderson, J. C., Pozo, O. D., Gu, Y.-Q., Tang, X., and Martin, G. B. (2004). Silencing of subfamily I of protein phosphatase 2A catalytic subunits results in activation of plant defense responses and localized cell death. Plant J. 38, 563-577. doi: 10.1111/j.1365-313X.2004.02073.x

He, X., Jin, C., Li, G., You, G., Zhou, X., and Zheng, S. J. (2008). Use of the modified viral satellite DNA vector to silence mineral nutrition-related genes in plants: silencing of the tomato ferric chelate reductase gene, FRO1, as an example. Sci. China C Life Sci. 51, 402-409. doi: 10.1007/s11427-0080066-0

Hema, R., Ding, X., and Nelson, R. (2013). Rationale for developing new virus vectors to analyze gene function in grasses through virus-induced gene silencing. Methods Mol. Biol. 975, 15-32. doi: 10.1007/978-1-62703-278-0_2

Hirai, M. Y., Yano, M., Goodenowe, D. B., Kanaya, S., Kimura, T., Awazuhara, M., et al. (2004). Integration of transcriptomics and metabolomics for understanding of global responses to nutritional stresses in Arabidopsis thaliana. Proc. Natl. Acad. Sci. U.S.A. 101, 10205-10210. doi: 10.1073/pnas.0403218101

Hiriart, J. B., Aro, E. M., and Lehto, K. (2003). Dynamics of the VIGS-mediated chimeric silencing of the Nicotiana benthamiana $\mathrm{ChlH}$ gene and of the Tobacco mosaic virus vector. Mol. Plant Microbe. Interact. 16, 99-106. doi: 10.1094/MPMI.2003.16.2.99

Hong, J. K., Choi, H. W., Hwang, I. S., Kim, D. S., Kim, N. H., Choi, D. S., et al. (2008). Function of a novel GDSL-type pepper lipase gene, CaGLIP1, in disease susceptibility and abiotic stress tolerance. Planta 227, 539-558. doi: 10.1007/s00425-007-0637-5

Hong, J. K., Jung, H. W., Lee, B. K., Lee, S. C., Lee, Y. K., and Hwang, B. K. (2004). An osmotin-like protein gene, CAOSM1, from pepper: differential expression and in situ localization of its mRNA during pathogen infection and abiotic stress. Physiol. Mol. Plant 64, 301-310. doi: 10.1016/j.pmpp.2004. 10.004

Jiang, X., Zhang, C., Lü, P., Jiang, G., Liu, X., Dai, F., et al. (2014). RhNAC3, a stress-associated NAC transcription factor, has a role in dehydration tolerance through regulating osmotic stress-related genes in rose petals. Plant Biotechnol. J. 12, 38-48. doi: 10.1111/pbi.12114

Kanazawa, A., Inaba, J., Kasai, M., Shimura, H., and Masuta, C. (2011). RNAmediated epigenetic modifications of an endogenous gene targeted by a viral vector: a potent gene silencing system to produce a plant that does not carry a transgene but has altered traits. Plant Signal. Behav. 6, 1090-1093. doi: $10.4161 /$ psb.6.8.16046
Kang, G., Li, G., Ma, H., Wang, C., and Guo, T. (2013). Proteomic analysis on the leaves of TaBTF3 gene virus-induced silenced wheat plants may reveal its regulatory mechanism. J. Proteomics 83, 130-143. doi: 10.1016/j.jprot.2013.03.020

Koiwa, H., Bressan, R. A., and Hasegawa, P. M. (2006). Identification of plant stressresponsive determinants in Arabidopsis by large-scale forward genetic screens. J. Exp. Bot. 57, 1119-1128. doi: 10.1093/jxb/erj093

Kotakis, C., Vrettos, N., Kotsis, D., Tsagris, M., Kotzabasis, K., and Kalantidis, K. (2010). Light intensity affects RNA silencing of a transgene in Nicotiana benthamiana plants. BMC Plant Biol. 10:220. doi: 10.1186/1471-2229-10-220

Kuzuoglu-Ozturk, D., Cebeci Yalcinkaya, O., Akpinar, B. A., Mitou, G., Korkmaz, G., Gozuacik, D., et al. (2012). Autophagy-related gene, TdAtg8, in wild emmer wheat plays a role in drought and osmotic stress response. Planta 236, 1081-1092. doi: 10.1007/s00425-012-1657-3

Lange, M., Yellina, A., Orashakova, S., and Becker, A. (2013). "Virus-induced gene silencing (VIGS) in plants: an overview of target species and the Virus-derived vector systems," in Virus-Induced Gene Silencing, ed A. Becker (New York, NY: Humana Press), 1-14.

Lee, S. C., Choi, D. S., Hwang, I. S., and Hwang, B. K. (2010). The pepper oxidoreductase CaOXR1 interacts with the transcription factor CaRAV1 and is required for salt and osmotic stress tolerance. Plant Mol. Biol. 73, 409-424. doi: 10.1007/s11103-010-9629-0

Lee, S. C., and Hwang, B. K. (2009). Functional roles of the pepper antimicrobial protein gene, CaAMP1, in abscisic acid signaling, and salt and drought tolerance in Arabidopsis. Planta 229, 383-391. doi: 10.1007/s00425-008-0837-7

Li, C., Yan, J. M., Li, Y. Z., Zhang, Z. C., Wang, Q. L., and Liang, Y. (2013). Silencing the SpMPK1, SpMPK2, and SpMPK3 genes in tomato reduces abscisic acid-mediated drought tolerance. Int. J. Mol. Sci. 14, 21983-21996. doi: 10.3390/ijms141121983

Li, W. X., and Ding, S. W. (2001). Viral suppressors of RNA silencing. Curr. Opin. Biotechnol. 12, 150-154. doi: 10.1016/S0958-1669(00)00190-7

Liang, J., Deng, G., Long, H., Pan, Z., Wang, C., Cai, P., et al. (2012). Virus-induced silencing of genes encoding LEA protein in Tibetan hulless barley (Hordeum vulgare ssp. vulgare) and their relationship to drought tolerance. Mol. Breed. 30, 441-451. doi: 10.1007/s11032-011-9633-3

Lim, C. W., and Lee, S. C. (2014). Functional roles of the pepper MLO protein gene, CaMLO2, in abscisic acid signaling and drought sensitivity. Plant Mol. Biol. 85 , 1-10. doi: 10.1007/s11103-11013-10155-11108

Liu, D., Liu, X., Meng, Y., Sun, C., Tang, H., Jiang, Y., et al. (2013). An organ-specific role for ethylene in rose petal expansion during dehydration and rehydration. J. Exp. Bot. 64, 2333-2344. doi: 10.1093/jxb/ert092

Liu, H., Reavy, B., Swanson, M., and Macfarlane, S. A. (2002a). Functional replacement of the Tobacco rattle virus cysteine-rich protein by pathogenicity proteins from unrelated plant viruses. Virology 298, 232-239. doi: 10.1006/viro.2002.1421

Liu, Y., Nakayama, N., Schiff, M., Litt, A., Irish, V., and Dinesh-Kumar, S. P. (2004). Virus induced gene silencing of a DEFICIENS ortholog in Nicotiana benthamiana. Plant Mol. Biol. 54, 701-711. doi: 10.1023/B:PLAN.0000040899.53378.83

Liu, Y., Schiff, M., and Dinesh-Kumar, S. P. (2002b). Virus-induced gene silencing in tomato. Plant J. 31, 777-786. doi: 10.1046/j.1365-313X.2002.01394.x

Luo, T., Fan, T., Liu, Y., Rothbart, M., Yu, J., Zhou, S., et al. (2012). Thioredoxin redox regulates ATPase activity of magnesium chelatase CHLI subunit and modulates redox-mediated signaling in tetrapyrrole biosynthesis and homeostasis of reactive oxygen species in pea plants. Plant Physiol. 159, 118-130. doi: $10.1104 /$ pp. 112.195446

Macfarlane, S. A. (1999). Molecular biology of the tobraviruses. J. Gen. Virol. 80(pt 11), 2799-2807.

Manmathan, H., Shaner, D., Snelling, J., Tisserat, N., and Lapitan, N. (2013). Virus-induced gene silencing of Arabidopsis thaliana gene homologues in wheat identifies genes conferring improved drought tolerance. J. Exp. Bot. 64, 1381-1392. doi: 10.1093/jxb/ert003

Martín-Hernández, A. M., and Baulcombe, D. C. (2008). Tobacco rattle Virus 16Kilodalton protein encodes a suppressor of RNA silencing that allows transient viral entry in meristems. J. Virol. 82, 4064-4071. doi: 10.1128/JVI.02438-07

Moeder, W., Del Pozo, O., Navarre, D. A., Martin, G. B., and Klessig, D. F. (2007). Aconitase plays a role in regulating resistance to oxidative stress and cell death in Arabidopsis and Nicotiana benthamiana. Plant Mol. Biol. 63, 273-287. doi: 10.1007/s11103-006-9087-x

Morel, J. B., Godon, C., Mourrain, P., Béclin, C., Boutet, S., Feuerbach, F., et al. (2002). Fertile hypomorphic ARGONAUTE (ago1) mutants impaired in 
post-transcriptional gene silencing and virus resistance. Plant Cell 14, 629-639. doi: 10.1105/tpc.010358

Morozova, O., and Marra, M. A. (2008). Applications of next-generation sequencing technologies in functional genomics. Genomics 92, 255-264. doi: 10.1016/j.ygeno.2008.07.001

Mourrain, P., Béclin, C., Elmayan, T., Feuerbach, F., Godon, C., Morel, J.-B., et al. (2000). Arabidopsis SGS2 and SGS3 genes are required for posttranscriptional gene silencing and natural virus resistance. Cell 101, 533-542. doi: 10.1016/S0092-8674(00)80863-6

Pastori, G. M., and Foyer, C. H. (2002). Common components, networks, and pathways of cross-tolerance to stress. The central role of "redox" and abscisic acid-mediated controls. Plant Physiol. 129, 460-468. doi: 10.1104/pp.011021

Pflieger, S., Richard, M. M. S., Blanchet, S., Meziadi, C., and Geffroy, V. (2013). VIGS technology: an attractive tool for functional genomics studies in legumes. Funct. Plant Biol. 40, 1234-1248. doi: 10.1071/FP13089

Purkayastha, A., and Dasgupta, I. (2009). Virus-induced gene silencing: a versatile tool for discovery of gene functions in plants. Plant Physiol. Biochem. 47, 967-976. doi: 10.1016/j.plaphy.2009.09.001

Qian, W., Yu, C., Qin, H., Liu, X., Zhang, A., Johansen, I. E., et al. (2007). Molecular and functional analysis of phosphomannomutase (PMM) from higher plants and genetic evidence for the involvement of PMM in ascorbic acid biosynthesis in Arabidopsis and Nicotiana benthamiana. Plant J. 49, 399-413. doi: 10.1111/j.1365-313X.2006.02967.x

Ramegowda, V., Senthil-Kumar, M., Udayakumar, M., and Mysore, K. S. (2013). A high-throughput virus-induced gene silencing protocol identifies genes involved in multi-stress tolerance. BMC Plant. Biol. 13:193. doi: 10.1186/14712229-13-193

Ratcliff, F., Martin-Hernandez, A. M., and Baulcombe, D. C. (2001). Technical Advance. Tobacco rattle virus as a vector for analysis of gene function by silencing. Plant J. 25, 237-245. doi: 10.1046/j.0960-7412.2000.00942.x

Ré, D. A., Dezar, C. A., Chan, R. L., Baldwin, I. T., and Bonaventure, G. (2011). Nicotiana attenuata NaHD20 plays a role in leaf ABA accumulation during water stress, benzylacetone emission from flowers, and the timing of bolting and flower transitions. J. Exp. Bot. 62, 155-166. doi: 10.1093/jxb/erq252

Robertson, D. (2004). VIGS vectors for gene silencing: many targets, many tools. Annu. Rev. Plant Biol. 55, 495-519. doi: 10.1146/annurev.arplant.55.031903. 141803

Romero, I., Tikunov, Y., and Bovy, A. (2011). Virus-induced gene silencing in detached tomatoes and biochemical effects of phytoene desaturase gene silencing. J. Plant Physiol. 168, 1129-1135. doi: 10.1016/j.jplph.2010.12.020

Ryu, C. M., Anand, A., Kang, L., and Mysore, K. S. (2004). Agrodrench: a novel and effective agroinoculation method for virus-induced gene silencing in roots and diverse Solanaceous species. Plant J. 40, 322-331. doi: 10.1111/j.1365313X.2004.02211.x

Saleki, R., Young, P. G., and Lefebvre, D. D. (1993). Mutants of Arabidopsis thaliana capable of germination under saline conditions. Plant Physiol. 101, 839-845.

Sarowar, S., Lee, J.-Y., Ahn, E.-R., and Pai, H.-S. (2008). A role of hexokinases in plant resistance to oxidative stress and pathogen infection. J. Plant Biol. 51, 341-346. doi: 10.1007/BF03036136

Scofield, S. R., and Nelson, R. S. (2009). Resources for virus-induced gene silencing in the grasses. Plant Physiol. 149, 152-157. doi: 10.1104/pp.108.128702

Senthil-Kumar, M., Govind, G., Kang, L., Mysore, K. S., and Udayakumar, M. (2007). Functional characterization of Nicotiana benthamiana homologs of peanut water deficit-induced genes by virus-induced gene silencing. Planta 225, 523-539. doi: 10.1007/s00425-006-0367-0

Senthil-Kumar, M., and Mysore, K. S. (2011a). New dimensions for VIGS in plant functional genomics. Trends Plant Sci. 16, 656-665. doi: 10.1016/j.tplants.2011.08.006

Senthil-Kumar, M., and Mysore, K. S. (2011b). Virus-induced gene silencing can persist for more than 2 years and also be transmitted to progeny seedlings in Nicotiana benthamiana and tomato. Plant Biotechnol. J. 9, 797-806. doi: 10.1111/j.1467-7652.2011.00589.x

Senthil-Kumar, M., and Mysore, K. S. (2014). Tobacco rattle virus-based virusinduced gene silencing in Nicotiana benthamiana. Nat. Protoc. 9, 1549-1562. doi: 10.1038/nprot.2014.092

Senthil-Kumar, M., Rame Gowda, H. V., Hema, R., Mysore, K. S., and Udayakumar, M. (2008). Virus-induced gene silencing and its application in characterizing genes involved in water-deficit-stress tolerance. J. Plant Physiol. 165, 1404-1421. doi: 10.1016/j.jplph.2008.04.007
Senthil-Kumar, M., and Udayakumar, M. (2006). High-throughput virus-induced gene-silencing approach to assess the functional relevance of a moisture stress-induced cDNA homologous to lea4. J. Exp. Bot. 57, 2291-2302. doi: $10.1093 /$ jxb/erj200

Senthil-Kumar, M., and Udayakumar, M. (2010). "Post transcriptional gene silencing methods for functional characterization of abiotic stress responsive genes in plants," in Gene Silencing: Theory, Techniques and Applications, ed A. J. Catalano (New York, NY: Nova Science Publishers, Inc.).

Soares-Cavalcanti, N. M., Belarmino, L. C., Kido, E. A., Wanderley-Nogueira, A. C., Bezerra-Neto, J. P., Cavalcanti-Lira, R., et al. (2012). In silico identification of known osmotic stress responsive genes from Arabidopsis in soybean and Medicago. Genet. Mol. Biol. 35, 315-321. doi: 10.1590/S141547572012000200012

Stratmann, J. W., and Hind, S. R. (2011). Gene silencing goes viral and uncovers the private life of plants. Entomol. Exp. Appl. 140, 91-102. doi: 10.1111/j.15707458.2011.01147.x

Suzuki, N., Rivero, R. M., Shulaev, V., Blumwald, E., and Mittler, R. (2014). Abiotic and biotic stress combinations. New Phytol. 203, 32-43. doi: 10.1111/nph.12797

Takehisa, H., Sato, Y., Antonio, B. A., and Nagamura, Y. (2013). Global transcriptome profile of rice root in response to essential macronutrient deficiency. Plant Signal. Behav. 8, e24409. doi: 10.4161/psb.24409

Tang, Y., Wang, F., Zhao, J., Xie, K., Hong, Y., and Liu, Y. (2010). Virus-based microRNA expression for gene functional analysis in plants. Plant Physiol. 153, 632-641. doi: 10.1104/pp.110.155796

Tao, X., and Zhou, X. (2004). A modified viral satellite DNA that suppresses gene expression in plants. Plant J. 38, 850-860. doi: 10.1111/j.1365-313X.2004. 02087.x

Tian, J., Pei, H., Zhang, S., Chen, J., Chen, W., Yang, R., et al. (2014). TRV-GFP: a modified Tobacco rattle virus vector for efficient and visualizable analysis of gene function. J. Exp. Bot. 65, 311-322. doi: 10.1093/jxb/ert381

Tran, L. S., and Mochida, K. (2010). Identification and prediction of abiotic stress responsive transcription factors involved in abiotic stress signaling in soybean. Plant Signal. Behav. 5, 255-257. doi: 10.4161/psb.5.3.10550

Tuttle, J. R., Idris, A. M., Brown, J. K., Haigler, C. H., and Robertson, D. (2008). Geminivirus-mediated gene silencing from Cotton leaf crumple virus is enhanced by low temperature in cotton. Plant Physiol. 148, 41-50. doi: 10.1104/pp.108.123869

Unver, T., and Budak, H. (2009). Virus-induced gene silencing, a post transcriptional gene silencing method. Int. J. Plant Genomics 2009:198680. doi: $10.1155 / 2009 / 198680$

Valentine, T., Shaw, J., Blok, V. C., Phillips, M. S., Oparka, K. J., and Lacomme, C. (2004). Efficient virus-induced gene silencing in roots using a modified Tobacco rattle virus vector. Plant Physiol. 136, 3999-4009. doi: 10.1104/pp.104.051466

Virk, N., Liu, B., Zhang, H., Li, X., Zhang, Y., Li, D., et al. (2013). Tomato SIMPK4 is required for resistance against Botrytis cinerea and tolerance to drought stress. Acta Physiol. Plant 35, 1211-1221. doi: 10.1007/s11738-012-1160-2

Voinnet, O. (2001). RNA silencing as a plant immune system against viruses. Trends Genet. 17, 449-459. doi: 10.1016/S0168-9525(01)02367-8

Wang, Y., Ying, J., Kuzma, M., Chalifoux, M., Sample, A., McArthur, C., et al. (2005). Molecular tailoring of farnesylation for plant drought tolerance and yield protection. Plant J. 43, 413-424. doi: 10.1111/j.1365-313X.2005.02463.x

Wang, Y. H., Garvin, D. F., and Kochian, L. V. (2002). Rapid induction of regulatory and transporter genes in response to phosphorus, potassium, and iron deficiencies in tomato roots. Evidence for cross talk and root/rhizosphere-mediated signals. Plant Physiol. 130, 1361-1370. doi: 10.1104/pp.008854

Wani, S. H., Singh, N. B., Saini, H. K., Devi, L. P., and Monalisa, P. (2010). Expressed Sequenced Tags (ESTs) - a functional genomic approach for gene discovery. Int. J. Curr. Res. 5, 74-79.

Wilson, P. B., Estavillo, G. M., Field, K. J., Pornsiriwong, W., Carroll, A. J., Howell, K. A., et al. (2009). The nucleotidase/phosphatase SAL1 is a negative regulator of drought tolerance in Arabidopsis. Plant J. 58, 299-317. doi: 10.1111/j.1365313X.2008.03780.x

Xu, P., Chen, F., Mannas, J. P., Feldman, T., Sumner, L. W., and Roossinck, M. J. (2008). Virus infection improves drought tolerance. New Phytol. 180, 911-921. doi: 10.1111/j.1469-8137.2008.02627.x

Xu, P., Zhang, Y., Kang, L., Roossinck, M. J., and Mysore, K. S. (2006). Computational estimation and experimental verification of off-target silencing during posttranscriptional gene silencing in plants. Plant Physiol. 142, 429-440. doi: 10.1104/pp.106.083295 
Yuan-Ge, W., Xue, H., Wen-Ying, M., Zhao, X.-Q., Bin, L., and Yi-Ping, T. (2014). Wheat PROTON GRADIENT REGULATION 5 is involved in tolerance to photoinhibition. J. Int. Agric. 13, 1206-1215. doi: 10.1016/S2095-3119(13) 60604-8

Zhang, J., and Kirkham, M. B. (1994). Drought-stress-induced changes in activities of superoxide dismutase, catalase, and peroxidase in wheat species. Plant Cell Physiol. 35, 785-791.

Zhu, Q.-H., Eun, M., Han, C.-D., Kumar, C., Pereira, A., Ramachandran, S., et al. (2007). "Transposon insertional mutants: a resource for rice functional genomics," in Rice Functional Genomics (New York, NY: Springer), 223-271.

Conflict of Interest Statement: The authors declare that the research was conducted in the absence of any commercial or financial relationships that could be construed as a potential conflict of interest.
Received: 12 February 2014; accepted: 19 June 2014; published online: 08 July 2014. Citation: Ramegowda V, Mysore KS and Senthil-Kumar M (2014) Virus-induced gene silencing is a versatile tool for unraveling the functional relevance of multiple abiotic-stress-responsive genes in crop plants. Front. Plant Sci. 5:323. doi: 10.3389/ fpls.2014.00323

This article was submitted to Plant Genetics and Genomics, a section of the journal Frontiers in Plant Science.

Copyright (c) 2014 Ramegowda, Mysore and Senthil-Kumar. This is an openaccess article distributed under the terms of the Creative Commons Attribution License (CC BY). The use, distribution or reproduction in other forums is permitted, provided the original author(s) or licensor are credited and that the original publication in this journal is cited, in accordance with accepted academic practice. No use, distribution or reproduction is permitted which does not comply with these terms. 